\section{UNDERSTANDING DISEASE BURDEN, SEVERITY AND PROGRESSION IN PATIENTS WITH CUTANEOUS LUPUS ERYTHEMATOSUS IN A REAL-WORLD SETTING}

${ }^{1}$ B Hoskin, 'D Bell, 'S Lobosco, ${ }^{2} \mathrm{~A}$ Eldar-Lissai*, ${ }^{3} \mathrm{~J}$ Bornstein. ${ }^{7}$ Adelphi Group, Adelphi Real World, Maccelsfield, UK; ${ }^{2}$ Biogen, HEOR- Global Markt Access, Boston, USA; ${ }^{3}$ Biogen, Medical Director, Boston, USA

\subsection{6/lupus-2017-000215.278}

Background and aims Real-world data on Cutaneous Lupus Erythematosus (CLE) patients are scarce, limiting our understanding of the course and unmet need of this chronic disease.

Objectives To assess progression, clinical burden and drivers of severity amongst CLE patients.

Methods Data were drawn from a 2013 survey of 101 dermatologists across the US and EU (France, Germany, Italy, Spain and UK). Dermatologists provided evidence on treatment patterns, disease/clinical history, demographics for their next five consulting CLE patients. For analysis, CLE patients were categorised into groups based on their current severity reported by their physician. Descriptive statistics outline the clinical characteristics of included CLE patients. Drivers of physician severity classification were explored using stepwise logistic regression.

Results Final analyses included 496 CLE patients; 74\% were female; mean age at diagnosis $=39.6$ years; mean disease duration $=4.2$ years

Currently, 27\% of CLE patients are classified as moderateto-severe. Amongst these patients, severity remained the same since diagnosis for $72 \%$ whilst deteriorated for $10 \%$.

Clear clinical differences emerge between moderate-tosevere and mild CLE patients (Table 1)
Stepwise logistic regression results highlight the significance of remission and symptom burden, in severity classification; mild vs. moderate-severe (Table 2):

Conclusions Despite an average of 4 years since diagnosis, a sizeable proportion of CLE patients remain moderate-to-severe, indicating persistence, relapse or worsening. Results highlight unmet need for better disease control, particularly around remission and symptom burden. This study contributes to scant literature on CLE, informing our understanding in a real-world clinical setting, and supports development of appropriate interventions amongst uncontrolled patients.

\section{THE CHANGE OF COMPLEMENT REGULATORY PROTEINS AND DISEASE ACTIVITY OF SYSTEMIC LUPUS ERYTHEROMATOSUS}

JL Huang *, T Min Hua. Chang Gung Memorial Hospital, Paediatrics, Taoyuan, Taiwan R.O C

\subsection{6/lupus-2017-000215.279}

Background and aims Complement activation is one of the important pathogenesis of systemic lupus erythematosus (SLE), and it has been revealed to associate with the activity of SLE. Complement regulatory proteins (CRPs) play critical roles on the regulation of alternative complement pathway, however, studies focus on the CRPs during SLE flare-up remains limited. This study was to investigate the change of CRPs and end products of compliment activation on active and remission phases of SLE.

Methods Forty paediatric SLE patients were enrolled. The clinical manifestation, laboratory data, and serum CRPs, C5a, and C5b-9 on active and remission phases were analysed.

Results The mean age of patients was $13.9 \pm 3.8$ years with female predominant $(7: 1)$. The mean renal and non-renal

\begin{tabular}{|c|c|c|c|c|}
\hline & $\begin{array}{c}\text { Mild } \\
(n=358)\end{array}$ & $\begin{array}{l}\text { Moderate } \\
(\mathbf{n = 1 2 7})\end{array}$ & $\begin{array}{l}\text { Severe } \\
(\mathbf{n = 1 1 )}\end{array}$ & $\begin{array}{c}\text { Mod-Sey } \\
\text { Combined } \\
(n=138)\end{array}$ \\
\hline Time since diagnosis (years) & 4.3 & 3.7 & 6.7 & 3.9 \\
\hline Patient is currently in remission & $60 \%$ & $12 \%$ & $0 \%$ & $11 \%$ \\
\hline Patient has flared in the last 12 months & $21 \%$ & $31 \%$ & $73 \%$ & $35 \%$ \\
\hline $\begin{array}{l}\text { Number of flares patient has experienced in the last } 12 \text { months } \\
\text { (all patients) }\end{array}$ & 0.3 & 0.6 & 3.0 & 0.8 \\
\hline $\begin{array}{l}\text { Number of flares patient has experienced in the last } 12 \text { months } \\
\text { ("of patients who have flared in the last } 12 \text { months) }\end{array}$ & $\begin{array}{c}1.6 \\
(* n=74)\end{array}$ & $\begin{array}{c}2.1 \\
\left({ }^{*} n=40\right)\end{array}$ & $\begin{array}{c}4.1 \\
(* n=8)\end{array}$ & $\begin{array}{c}2.4 \\
(* n=48)\end{array}$ \\
\hline Patient experiencing systemic involvement & $9 \%$ & $26 \%$ & $50 \%$ & $28 \%$ \\
\hline Patient experiencing anxiety and/or depression & $12 \%$ & $20 \%$ & $55 \%$ & $32 \%$ \\
\hline $\begin{array}{cl}\text { Patient's current Dermatological/skin symptoms (top 3) } \\
-\quad \text { Discoid rash } \\
\text { - } \quad \text { Photosensitivity } \\
\text { - } \quad \text { Malar/'Butterfly rash }\end{array}$ & $\begin{array}{l}42 \% \\
40 \% \\
11 \%\end{array}$ & $\begin{array}{l}64 \% \\
69 \% \\
31 \%\end{array}$ & $\begin{array}{l}82 \% \\
64 \% \\
36 \%\end{array}$ & $\begin{array}{l}65 \% \\
68 \% \\
32 \%\end{array}$ \\
\hline $\begin{array}{l}\text { Number of tests conducted in the last } 12 \text { months (e.g. Barium x- } \\
\text { ray, MRI, ESR blood test etc.) }\end{array}$ & 13.7 & 17.4 & 16.6 & 17.3 \\
\hline Number of HCP consultations in the last 12 months & 5.1 & 6.0 & 8.5 & 6.2 \\
\hline
\end{tabular}

Abstract 278 Table 2

\begin{tabular}{|l|c|c|}
\hline & Odds ratio & P value \\
\hline Patient is in remission (vs. not) & 0.1298574 & $<0.001$ \\
\hline No. of current lupus symptoms & 1.247704 & $<0.001$ \\
\hline
\end{tabular}


SLEDAI at active and remission phases were 4.25 vs 0.45 and 8.32 vs 1.25 , respectively. Fever, rash, and arthritis were the most common features and kidney was the most common involved organ at active phase. The mean serum complement factor $\mathrm{H}$ and I levels at active phase were significantly lower than that at remission phase. The mean serum CD46 level at active phase was higher significantly compared with that at remission phase. The serum $\mathrm{C} 5 \mathrm{a}$ and $\mathrm{C} 5 \mathrm{~b}-9$ at active and remission phases were no significant difference. Five patients had sequelae including 1 intracranial haemorrhage and 4 chronic kidney disease.

Conclusions Serum complement factor H, I and CD46, but not C5a and C5b-9 were associated with disease activity of SLE.

\section{THE ROLE OF PI3K, MTOR IN THE EXPRESSION OF INTERFERON -ALPHA INDUCED PROTEIN IFIT4 IN LUPUS}

${ }^{1} \mathrm{~J}$ Chen, ${ }^{2}$ X Huang*. 'Xiang Ya Second Hospital, Department of Rheumatology, chang sha, China; ${ }^{2}$ Xiang Ya Second Hospital, Rheumatology, chang sha, China

10.1136/lupus-2017-000215.280

Background and aims The role of Phosphoinositide 3-kinase (PI3K), mammalian target of rapamycin (mTOR) and dexamethasone in IFN- $\alpha$-induced-human interferon-induced protein with tetratricopeptide repeats 4 (IFIT4) expression was investigated.

Methods HT1080 cells were pre-treated with specific inhibitors of $\mathrm{PI} 3 \mathrm{~K} / \mathrm{mTOR}$, PKC or JNK transduction factors, then further incubated with IFN- $\alpha$ for different times. The mRNA and protein expression of IFIT4 or other indicated signal transduction factors were detected by qRT-PCR or westernblot.

Results LY294002, a dual mTOR and PI3K inhibitor, but not wortmannin, blocked IFIT4 promoter activation, mRNA and protein, as well as phosphorylation of STAT1, JNK, PKC $\delta$ induced by IFN- $\alpha$. Interestingly, rapamycin, mTOR inhibitor, had the same effects as LY294002, counteracting the IFN- $\alpha$ dependent upregulation of IFIT4 and phosphorylation of STAT1, JNK, PKCס. Rottlerin or Sp600125, specific inhibitor of PKC $\delta$, JNK, inhibited IFN-induced IFIT4 expression, but not the phosphorylation of AKT and mTOR. Interestingly, in vivo, bolus intravenous injection of methylprednisolone rapidly decreased the IFIT4 expression. In vitro, dexamethasone could prohibit IFN- $\alpha$-induced IFIT4 transcription and the phosphorylation of STAT1, JNK, PKC- $\delta$.

Conclusions IFN- $\alpha$ activate the PI3K and mTOR pathways, which converge to regulate $\mathrm{PKC} \delta$, JNK , STAT1-dependent transcription of IFIT4 in a mTOR dependent and AKT independent manner. The induction of IFIT4 transcription by IFN- $\alpha$ depends upon sequential activation of mTOR, PKC $\delta$, JNK and STAT1. Steriod might play the role in treatment for systemic lupus erythematosus (SLE) partially by the reason of decreasing IFN alpha induced protein IFIT4 expression via sequential inhibition of the phosphorylation of PI3K, mTOR, PKC $\delta$, JNK, STAT1.

\section{THE CLINICAL ANALYSIS OF THE CHARACTERISTICS OF LUPUS MESENTERIC VASCULITIS (LMV) COMPARED WITH LUPUS NEPHRITIS}

${ }^{1} \mathrm{~J}$ Chen, ${ }^{2} \mathrm{R}$ Wan, ${ }^{3} \mathrm{X}$ Rong, ${ }^{3} \mathrm{R}$ Wang, ${ }^{4} \mathrm{X}$ Huang ${ }^{*} .{ }^{1}$ Xiang Ya Second Hospital, Department of Rheumatology, chang sha, China; ${ }^{2}$ West China school of medicine- Sichuan University-, Department of Rheumatology, Si Chuan, China; ${ }^{3}$ West China Hospital- Sichuan University, Department of Rhematology, Si Chuan, China; ${ }^{4}$ Xiang Ya Second Hospital, Rheumatology, chang sha, China

\subsection{6/lupus-2017-000215.281}

Background and aims Evaluate the clinical characteristics of lupus mesenteric vasculitis (LMV) in a large cohort.

Methods The in-patients with Systemic Lupus erythematosus (SLE) admitted to the West China Hospital from 2009 to 2015 were analysed. Diagnosis of LMV was made according to the clinical symptoms, abdominal image and the reaction to steroids. The patients with Lupus Nephritis (LN) were set as the control. Qualitative differences were analysed using the chi-square test.

Results Among 3143 patients with SLE, 103 patients were diagnosed as LMV with the incidence of LMV being $32.8 \%$. Among those patients with LMV, 96.1\% was female and the average age was 35.8 years old, 37 (35.9\%) patients were diagnosed as SLE with LMV as the one of onset symptoms, $54(52.4 \%)$ patients were misdiagnosed at the first time. The incidence of abdominal pain was $87.4 \%$, while that of pelvic effusion $68.04 \%$, vomiting $70.9 \%$, bloating $68.6 \%$ and diarrhoea $67.0 \%$. Their average score of the SLE disease activity index (SLEDAI ) (including LMV as vasculitis ) was 21.8 \pm 7.7 . During the following-up for 2-96 months, partial remission of the incidence of abdominal pain within a week was $87.9 \%$, and $98.8 \%$ of the LMV patients got complete remission in a month. Eight cases experienced disease relapse (8.0\%). Rash $\left(X^{2}=6.7255, \quad \mathrm{p}=0.0095\right), \quad$ high creatinine $\left(X^{2}=6.746\right.$, $\mathrm{p}<0.0001)$, hypercholesterolemia $\left(\mathrm{X}^{2}=21.2986, \mathrm{p}<0.0001\right)$, leukopenia $\left(\mathrm{X}^{2}=7.4153, \mathrm{p}=0.0245\right)$ were presented more often in the patients with LMV than in LN.

Conclusions There were differences between LMV and LN in clinical symptoms and laboratory findings. A much lower mortality rate was found in LMV.

\section{EFFECT OF GLUTEN CONTAINING DIET ON PRISTANE INDUCED LUPUS PRONE MICE}

N Hussain*1 'University of the punjab, Microbiology and molecular genetics, Lahore, Pakistan

\subsection{6/lupus-2017-000215.282}

Background and aims SLE is a chronic autoimmune disease with characteristic organ involvement and autoantibodies production. The pathogenicity and aetiology of the disease yet to be elucidated. It is presently accepted that environmental factors trigger the disease in genetically sensitive individuals. Gluten, a protein fraction commonly found in wheat grains, associated with food related disorders and a number of autoimmune diseases. We hypothesised that gluten containing diet would further exacerbate an already undergoing arbitrary immune reaction in SLE patients. 